\title{
Entre a crítica, o público e o autor: construção de sentido e crítica social em Brave New World de Aldous Huxley
}

\section{Among the critics, the audience and the author: construction of meaning and social criticism in Brave New World by Aldous Huxley}

\author{
Rafael da Cunba Duarte Francisco* \\ rafaelcfrancisco@hotmail.com
}

Resumo:

Esse trabalho tem como principal objetivo discutir o projeto estético criado por Aldous Huxley em seus romances distópicos, especialmente em Brave New World primeiramente publicado em 1932. A partir da comparação com alguns outros romances distópicos do mesmo período, pretendemos demonstrar como parece haver na obra de Huxley um projeto estético que se situa entre a crítica especializada, seu público e a representação de si mesmo como alguém apto a prognosticar o futuro por meio de seu romance. Ao abordarmos a questão da morte no interior da trama ficcional, pretendemos apresentar ao leitor como esse prognóstico tenta validar-se, com mais ou menos sucesso, diante de seu público como o futuro a ser encarado pelos homens e mulheres das próximas gerações.

Palavras-chave: Aldous Huxley; Distopia; Morte

\begin{abstract}
:
This paper aims to discuss the aesthetic project created by Aldous Huxley in his dystopian novels, especially in Brave New World, first published in 1932. From the comparison with some other dystopian novels of the same period, we intend to demonstrate how there seems to exist on Huxley's work an aesthetic project that is among the critics, the public and a representation of himself as someone who can forsee the future through his novel. In addressing the issue of death within the fictional plot, we intend to present to the reader how this prognosis tries to validate itself, with more or less success, before his audience like the future to be faced by the men and women of the next generations.
\end{abstract}

Keywords: Aldous Huxley; Dystopia; Death

\footnotetext{
* Doutorando ligado ao Programa de pós-graduação em História Social (PPGHIS) da UFRJ sob a orientação do professor Dr. Felipe Charbel. rafaelcfrancisco@hotmail.com
} 
Artigos

Os romances distópicos já foram exaustivamente estudados pelos mais diversos campos das humanidades. Desde a segunda metade do século XX, trabalhos oriundos dos estudos literários, da filosofia, das ciências sociais e da História tomaram, de diversas formas e com abordagens múltiplas, alguns aspectos dessas obras literárias como seus objetos de pesquisa. A força dessa tradição literária também pode ser verificada no cenário do romance contemporâneo. ${ }^{1}$ Escritores como Italo Calvino, em As cidades Invisíveis, e Haruki Murakami, em sua trilogia 1Q84, foram profundamente influenciados pelas obras de Aldous Huxley e George Orwell.

Diante dessas múltiplas leituras e apropriações, faz-se necessário indagar: pode-se falar de uma nova forma literária? E em caso afirmativo; qual é a novidade trazida por esses romances distópicos para a tradição literária europeia? Para essas perguntas, aparentemente podem haver duas respostas distintas. A primeira, explorada extensivamente ao longo do século XX pela crítica literária especializada norte-americana, consiste em analisar uma obra como a de Aldous Huxley, incluindo aqui os seus romances distópicos (Brave New World e The Island) como sátiras à sociedade de seu tempo 2 e, dessa forma, considerando-o como um "modernista relutante". (FIRCHOW, 2002).

Essa noção deriva da crença de que os romances distópicos da primeira metade do século XX são críticas a um determinado contexto de "crise da cultura". Tal crença é recorrente também nas formulações do filósofo alemão Isaiah Berlin, que considera as distopias escritas por Huxley, Orwell e Zamyatin na primeira metade do século XX como meros produtos desse estado de crise. $\mathrm{O}$ autor relaciona diretamente o surgimento das antiutopias (ou distopias) à derrocada de certo tipo de "filosofia perene" que, nas palavras do autor,

“com suas verdades objetivas e inalteráveis fundamentadas na percepção de uma ordem eterna por trás do caos das aparências, foi lançada na defensiva com os ataques de relativistas, pluralistas, irracionalistas, pragmatistas, subjetivistas, e certos empiricistas. Com o declínio dessa filosofia, o conceito de sociedade perfeita, que deriva dessa grande visão unitária, perde seu poder de persuasão." (BERLIN, 1991, p. 48)

Dessa perda de força, surgiriam o "protesto - e as antiutopias - de Aldous Huxley, Orwell e Zamyatin" nas quais "o próprio fluxo da vida humana é brutalmente reduzido à uniformidade." (Ibid, p. 48-49)

Essa visão clássica sobre o declínio da utopia enquanto uma proposta social já foi explorada também por outros trabalhos, tomando objetos diferentes em suas análises. ${ }^{3}$ Entretanto, assumir essa postura diante das questões propostas por nós na página anterior seria igualmente assumir que uma obra literária é, em última instância, um reflexo do contexto histórico no qual ela foi produzida e que, direta ou indiretamente, busca representar. Por outro lado, essa resposta jamais permitiria com que os romances distópicos pudessem se tornar, eles mesmos, objeto de nossa pesquisa, isso porque ao aceitarmos a visão de que, por exemplo, uma produção ficcional como a de Aldous Huxley consistia em um conjunto de "romances satíricos de ideias" que teria como finalidade última a crítica da sociedade na qual esses romances haviam sido escritos, estaríamos negando uma face outra de atuação da literatura, face essa que busca não só reagir a certas pressões históricas, mas também atuar nela, transformando essa realidade representada pelo romance.

Contudo, negar o aspecto crítico da distopia como a novidade trazida por esses romances não significa propriamente recusar sua existência, mas apenas ressaltar que as relações entre a ficção entendida aqui como atos de fingir (ISER, 1996) e a dimensão histórica desses romances pode ter se dado de outras maneiras que até então não haviam sido experimentadas no cenário do romance europeu. Assim, ainda permanecem as perguntas iniciais, ou seja, como poderíamos falar de uma nova forma romanesca e quais seriam as novidades trazidas por esses romances distópicos para a tradição literária europeia?

1 Dentre os muitos exemplos dos mais diverssos campos dos estudos que poderíamos oferecer ao leitor, ver especialmente: (CALDER, 1976), (PAVLOSKI, 2012), GRUSHOW, 1962, p 42-45) e também (WILLIAMS, 2011). Nessas obras, as distopias literárias são estudadas a partir de um amplo espectro de questões que vão desde a filosofia, passando pela crítica literária e finalmente chegando à própria História Literária.

2 Para um exemplo de como esse pensamento desenvolve-se, ver: (MECKIER, 2006).

3 Ver, por exemplo: (KOSELLECK, 1999) no qual o autor, a partir do declínio das propostas utópicas contidas em diversas filosofias da história, procura interpretar e compreender um processo de crise da modernidade. Outro exemplo encontra-se em: (HABERMAS, 2005. p. 14), na qual o autor afirma que "esse esgotamento [das energias utópicas] pode configurar uma mudança no espírito do tempo em geral. Talvez o amálgama que unia o pensamento utópico e histórico se dissolva novamente; talvez a estrutura do espírito do tempo e o estado de agregação política se transformem."

4 Para um exemplo sobre como o autor desenvolve o conceito de "romance satírico", ver novamente: (MECKIER, 2006). 
A segunda via, pela qual nosso trabalho pretende desenvolver-se, volta-se para a questão das múltiplas temporalidades que atravessam não só as obras distópicas de Aldous Huxley, mas também seus ensaios. Nesse ponto, não se trata propriamente da relação dos romances distópicos com a representação de uma sociedade futura, ou seja, da mera relação existente entre presente e futuro dentro do enredo desses romances. Essa não é uma característica apenas desse conjunto de obras. Desde a Utopia de Thomas More, passando pela Cidade do Sol de Campanella e chegando aos utopistas ingleses do Século XIX, como William Morris, a questão da relação entre as suas obras literárias e um certo futuro - ou um outro lugar paradisíaco - a ser representado por elas estava posta.

Portanto, esse novo elemento não consiste exatamente na tematização, a partir da ficção, de um futuro distante dos homens. O que nos interessa como fator de destaque na análise dessas obras é o estatuto assumido pelo ficcional nesse movimento de representação, ou seja, como esses atos de fingir ${ }^{6}$ são mobilizados no interior desses enredos de uma maneira muito particular. Assim, a pergunta proposta inicialmente só pode ser respondida com outra questão: qual é a especificidade do estatuto ficcional dessas obras?

Em Auerbach, o romance do século XX é analisado a partir das obras Viagem ao Farol (To The Lighthouse) de Virginia Woolf, Em busca do tempo perdido (À la recherche du temps perdu) de Marcel Proust e também Ulisses (Ulysses) de James Joyce. Para o filólogo alemão, o realismo desse período é marcado por uma crescente introspecção e subjetivação dos seus personagens, algo conhecido no âmbito da teoria literária como o "fluxo da consciência" (Stream of Consciousness). ${ }^{7}$ A despeito do tom excessivamente hegeliano", explicitado principalmente no epílogo quando Auerbach elege o "realismo moderno", que já vinha sendo gestado nos séculos anteriores, como a mais rica forma de representação, ou seja, a mais capaz de dar conta da complexidade da existência humana, o realismo pensado por Erich Auerbach contribuirá diretamente para o desenvolvimento de nossos argumentos (AUERBACH, 2011, p. 500).

Entretanto, é notório como a narrativa de Brave New Worldou mesmo de outros romances distópicos como Wede Zamyatin e 1984escrito por Orwell se distanciam do que Auerbach entende como a marca principal desse realismo moderno. Não há em nenhum dos três romances um acentuado fluxo da consciência no qual os protagonistas perdem-se em seus próprios pensamentos e no qual o próprio narrador possui pouco domínio sobre os anseios de seus personagens.

Mas é justamente a abertura de possibilidades que essa definição sobre realismo nos oferece que torna Auerbach fundamental para se responder à nossa pergunta. A ideia de múltiplos realismos derivada da compreensão desse mesmo realismo menos como um estilo de época do que como o reconhecimento de um movimento de reescrição da realidade a partir da literatura nos dá subsídios suficientes para pensarmos de que maneira a ficção atua nos romances distópicos. Não se encaixar naquilo a que Auerbach chama como "realismo moderno"não significa dizer que esses romances não são realistas, ou seja, que não há uma certa representação da realidade neles contida. O que isso quer dizer é apenas que essa representação da realidade e também seu estatuto ficcional são diferentes. Essa diferença abre o espaço para pensarmos em outros realismos que ambicionam, a partir de suas próprias práticas narrativas, representar outros aspectos da realidade ocidental.

5 Por exemplo, no caso da Utopia de More, Carlo Ginzburg afirma que "na ficção jocosa encenada por More e seus amigos, podemos distinguir dois gestos contraditórios: de um lado, semear os próprios escritos de detalhes concretos, voltados a comprovar a veracidade dos mesmos; de outro, dar a entender, por vários expedientes, que se tratava de narrativas completamente inventadas." A partir disso, percebemos como o gênero utópico se estabelece entre uma espécie de narrativa fantástica e um desejo de narrar o real. Cf. (GINZBURG, 2004. p. 25). Numa outra perspectiva, preocupada em analisar a temporalização do conceito de utopia entre os séculos XVI-XIX, ver: (KOSELLECK, 2012).

6 Os atos de fingir, para Wolfgang Iser, consistem em três mecanismos (seleção, combinação e autodesnudamento) a partir dos quais se dá o processo de criação ficcional. Cada um desses mecanismos tem uma função específica na construção literária, sendo os dois primeiros mais ligados à transgressão dos limites entre texto e contexto histórico e o terceiro consiste na apresentação da própria ficção como aquilo que ela se pretende, ou seja, um ato de encenação. Cf. (ISER, 1996, p. 15. e p. 24-25)

7 Para um maior aprofundamento sobre como esse estilo narrativo se consolida nos romances da primeira metade do século XX, Cf.(AUERBACH, 2011). Especialmente o ultimo capítulo sobre o livro "To the lighthouse" da escritora Virginia Woolf, no qual o autor percebe uma mudança significativa na forma como o "fluxo da consciência" é apresentado aos leitores, não mais sendo o movimento objetivo realizado pelo escritor que anteriormente possuía um conhecimento total sobre a realidade de seus personagens, mas pelo contrário, como um meio pelo qual o autor questiona, duvida e interroga os seus personagens, como se a verdade acerca deles fosse desconhecida para o próprio autor.

8 Acerca da existência de uma concepção teleológica em Auerbach, ver especificamente: LIMA, 2009, p. 121)no qual o autor aborda como “a herança hegeliana se instala na interpretação de Auerbach sobre a literatura ocidental mesmo contra a sua vontade.” (tradução nossa) 
Artigos

Para isso, o caminho de uma análise que reduza esse conjunto de romances a uma mera resposta às pressões históricas de um contexto de "crise da cultura" tem pouco a oferecer para o desenvolvimento desse trabalho. A alternativa que se apresenta em contraposição à anterior seria investigar, a partir das próprias formulações de Aldous Huxley, quais são as concepções que orientam sua visão acerca da ficção como mecanismo de encenação e do romance como forma de representação da vida.

Assim, perguntar-se pelo estatuto ficcional dos romances distópicos é fundamental, entretanto, essa pergunta não pode ser posta de fora para dentro, ou seja, decerta realidade histórica que informa a construção dessas obras, mas sim partir do interior das questões formuladas pelos seus autores. Isso não significa excluir a importância da pressão exercida pela História nas obras literárias, mas antes consiste em repensar a maneira pela qual nós, historiadores, temos formulado nossas perguntas. Portanto, propomos outra via que privilegie pensar o desenvolvimento de nossas hipóteses a partir de dentro da obra do autor, não aceitando como naturais alguns contextos previamente dados e, para isso, os ensaios de Aldous Huxley oferecem as condições ideais.

\section{A morte como erradicação do indivíduo em Brave New World de Aldous Huxley:}

Diferentemente do que ocorre em Zamyatin e Orwell, no romance de Huxley a morte não ocorre apenas de forma metafórica, ou seja, não é apenas o momento no qual o protagonista é afastado daquilo a que se poderia chamar de vida do espírito, ${ }^{9}$ mas também consiste em uma experiência literal na medida em que, na passagem final do romance, o Selvagem opta por suicidar-se, dando um final ao processo iniciado com sua viagem da reserva para Londres. Todavia, antes de escolher dar fim a sua própria vida, o protagonista tenta, assim como os de Orwell e Zamyatin, combater o sistema distópico. Em Huxley, não há um movimento organizado contrário aos Administradores Mundiais, nem um realmente consolidado (Zamyatin) ou outro criado pelo Estado (Orwell). A revolta do Selvagem não é politicamente organizada ou dirigida por um plano cuidadosamente elaborado de tomada do poder. Pelo contrário, o momento no qual John passa a perceber - a partir da morte de sua mãe - que esse admirável mundo novo não coincidia com as histórias maravilhosas contadas por ela nos tempos passados na reserva, é também o instante em que o herói mais se afasta de uma conduta razoavelmente racional. Observando como as forças do governo faziam uso da distribuição gratuita do soma (HUXLEY, 1991, p. 45) ${ }^{10}$ para manter a estrutura hierárquica dessa sociedade sob controle, o Selvagem revolta-se contra esse Estado de coisas e decide tentar trazer os outros cidadãos londrinos de volta à razão. A passagem se desenrola da seguinte forma:

O pessoal subalterno do Hospital de Park Lane para Moribundos compunha-se de cento e sessenta e dois Deltas, divididos em dois grupos Bokanovsky, de oitenta e quatro gêmeas ruivas e setenta e oito gêmeos dolicocéfalos [dolicocephalic] morenos, respectivamente. Às seis horas, terminado o seu dia de trabalho, reuniam-se no vestíbulo do Hospital e recebiam do Subecônomo Assistente [Depury Sub-Bursar] a sua ração de soma.

9 A vida do espírito seria marcada, para Hannah Arendt, por suas três funções fundamentais: o intelecto, designado pela autora de o pensar, a volição, correspondente ao desejo dos homens, e por último o juízo, do qual a autora, embora não tenha completado seus escritos em virtude de sua morte, seja largamente tributária de uma tradição de pensamento kantiano. Recorre-se à expressão mais por sua versão original do que pela tradução clássica para o português na qual o termo mind transforma-se em espírito, no sentido usualmente atribuído ao termo na tradição de pensamento francesa. O que importa para nós, nesse termo, é o aforisma de Paul Valery do qual Hannah Arendt se apropria em sua obra: tantôt je pense et tantôt je suis (às vezes sou, às vezes penso) que marca decisivamente a instrospecção desconfortável experimentada pelo selvagem no romance. Arrastado abruptamente para a condição de ser que ora pensa e ora vive pelas suas paixões, o herói invariavelmente adentra aquele campo da existência política que será profundamente alterada pela luta contra o sistema opressor, luta que o prognóstico de Huxley já dá como perdida de antemão. Para um maior aprofundamento na questão, ver: (ARENDT, 2008).

10 O soma era uma droga distribuída pelo governo a todos os setores da sociedade distópica que causava uma sensação de torpor e felicidade instantâneas em seus usuários. A droga, no sistema elaborado por Huxley, era um dos pilares de sustentação do regime na medida em que era uma das principais responsáveis pela sensação de satisfação perene entre todos os habitantes. A passagem seguinte deixa bem clara a função central exercida pelo fármaco na estrutura social mundo novista: "Era aquele animal de Henry Foster. - Você precisa é de um grama de soma.

- Todas as vantagens do Cristianismo e do álcool; nenhum dos seus inconvenientes.” (tradução nossa) 
Saindo do elevador, o Selvagem irrompeu por entre eles. Mas seu espírito[mind] estava longe dali - com a morte, com a sua dor, com o seu remorso; maquinalmente, sem ter consciência do que fazia, começou a abrir caminho, aos empurrões, através da multidão.

- Agora - disse em tom peremptório [o funcionário responsável] - façam o favor de aproximar-se. Um de cada vez e nada de empurrões. Um por um, e sem atropelos, os gêmeos adiantaram-se. Primeiro, dois homens; depois, uma mulher; a seguir, outro homem; logo após, três mulheres; depois...

- O Selvagem permanecia ali, contemplando a cena. «Oh, admirável mundo novo! Oh, admirável mundo novo!..." Em seu espirito[mind], as palavras cantantes pareciam ter mudado de tom. Elas o haviam escarnecido na sua dor e no seu remorso; haviam-no escarnecido, e com que horrendo acento de zombaria cínica! (Ibid, p. 171-172) ${ }^{11}$

Aqui começa a ser desenhada, ainda de maneira insípida, a ruína do Selvagem. Logo após receber a notícia da morte de Linda (sua mãe), John fica transtornado com a situação e decide avançar em direção às filas recém-formadas para o recebimento da ração diária de soma. Em um primeiro momento, suas ações não possuem qualquer relação com o evento que está se desenrolando a sua volta. Na realidade, as palavras provocativas não ecoavam de nenhum dos gêmeos Deltas (funcionários do hospital) ou do Subecônomo Assistente (responsável pela distribuição do soma), mas sim do seu espírito (mind). Sentindo-se zombado pela tradição que o havia educado e formado para um mundo que já não mais existe, o Selvagem finalmente toma consciência de sua própria condição no interior desse Admirável Mundo Novo. A inquietação surgida dentro de seu espírito agora ganhará vida em forma de ação, quando o Selvagem percebe, em um lampejo de lucidez, o que havia sido Linda no interior dessa sociedade e, principalmente, o que deveria ser feito a seguir:

Linda tinha sido uma escrava, Linda morrera; outros, pelo menos, viveriam livres e a beleza brilharia sobre o mundo. Era uma reparação, um dever. E, subitamente, o Selvagem viu com uma clareza cristalina o que tinha a fazer; foi como se tivessem aberto uma janela, como se tivessem afastado uma cortina.

- Vamos - disse o Subecônomo. Outra mulher de cáqui adiantou-se.

- Parem! - gritou o Selvagem, com voz retumbante. - Parem!

Abriu caminho até a mesa; os Deltas fitaram-no com assombro.

- Ford! - disse o Subecônomo Assistente, a meia voz. - É o Selvagem! - Ele se sentiu assustado.

- Ouçam-me, suplico-lhes - bradou o Selvagem com ardor. - Emprestem-me seus ouvidos... - Nunca falara em público, e tinha muita dificuldade em expressar o que queria dizer. - Não tomem essa droga horrível. É veneno, é veneno.

- Escute, Sr. Selvagem - disse o Subecônomo Assistente, com um sorriso conciliador - não se importaria de deixar que eu...

- Veneno para a alma [soul, assim como para o corpo. (Ibid, p. 173) ${ }^{12}$

11 No original, em inglês, encontra-se: “'The menial staff of thge Park Lane Hospital for the dying consisted of one hundred and sixty-two Deltas divided into two Bokanovsky groups of eighty-four red-headed female and seventy-eight dark dolicocephalic male twins, respectively. At six, when their working day was over, the two groups assembled in the vestibule of the hospital and were served by the Depury Sub-Bursar with their soma ration. From the lift the savage stepped out into the midst of them. But his mind was elsewhere - with death, with his grief, and his remorse; mechanically, without counsciousness of what he was doing, he began to shoulder his way into the crowd. [...]

Now, he said peremptorily, 'step foward, please. One at a time, and no shoving. One at a time, with no shoving, the tiwns stepped forward. First two males, then a female, then another male, then three females, then...

The savage stood looking on. 'O brave new world, O brave new world...' In his mind the singning words seemed to change their tone. They had mocked him through his misery and remorse, mocked him with how hideous a note of cynical derision!' (tradução nossa, embora os termos especificamente criados por Huxley - dolicocephaliceDepury Sub-Bursar - tenham sido copiados da tradução brasileira realizada por Vidal de Oliveira e LinoVallandro para a versão publicada pela editora Globo em 1979 que consta nas referências desse texto).

12 No original, em inglês, encontra-se: "Linda had been a slave, Linda had died; others should live in freedom, and the world be made beautiful. A reparation, a duty. And suddenly it was luminously clear to the Savage what he must do; it was as though a shutter had been opened, a curtain drawn back. 'Now', said Deputy-Bursar.

Another khaki female stepped foward.

'Stop!' called the savage in a loud and ringing voice. 'Stop!'

He pushed his way to the table; the deltas stared at him with astonishement

'Ford!' said Deputy Sub-bursar below his breath. It's the Savage.' He felt scared.

'Listen, I beg you', cried the Savage earnestly. 'Lend me your ears...' He had never spoken in public before, and found that horrible stuff. It's poison, It's poison.'

'I say, Mr. Savage,' said the Deputy Sub-Bursar, smiling propiatingly. 'Would you mind letting me...'

'Poison to the soul as well as body."' (tradução nossa) 
Artigos

A morte de Linda provoca em John uma tomada de consciência com a qual o jovem rapaz não parece apto a lidar. Perceber que esse admirável mundo novo escravizava seus cidadãos a partir do uso de diversos mecanismos de controle refinados dentre os quais o soma é apenas um dentre tantos outros faz com que o protagonista se rebele contra aquilo que fora narrado para ele como um paraíso idílico. A conexão imediata estabelecida pelo Selvagem é simples, mas bastante poderosa: o soma é um veneno para a alma (soul) que torna os homens não apenas escravos de seus senhores mas também e, principalmente, presos a uma infância eterna. O que muda drasticamente desse momento em diante é a percepção do herói frente a esse mundo no qual ele acabara de ingressar. Não se trata tanto de derrubar esse regime, mas sim de alertar aos outros como eles estão abrindo mão de suas próprias individualidades em função de uma falsa sensação de felicidade. O anseio do Selvagem não é, assim como o de Winston e o de D-503, a configuração de uma nova ordem social na qual os procedimentos e avanços científicos conquistados a duras penas pelos administradores mundiais fossem deixados de lado, mas sim um retorno ao mundo da tradição no qual as palavras de Shakespeare não soavam de maneira irônica em seu próprio espírito.

No interior da passagem supracitada, o narrador já prepara o leitor implícito para a derrota iminente de John em sua tentativa, extremamente débil em seus meios, de convencer os Deltas (a mais baixa casta do sistema de castas construído por Huxley em seu romance) a largarem o soma. Logicamente, o debate que se desenvolve aqui não consiste somente em sua contrariedade à condição trazida pela droga à totalidade dos habitantes dessa sociedade distópica, mas sim no conflito entre esse mundo idílico construído pelos administradores mundiais e um mundo antigo do qual John e o leitor implícito logo revelam-se os únicos partidários. O espanto de John é ocasionado especialmente ao deparar com pessoas totalmente alheias aos seus valores. Nesse momento da trama, o conflito já está desenhado e a sensação de que não há caminho possível para o retorno é narrativamente construída, encontrando seu momento derradeiro no diálogo entre Mustafá Mond e John. Essa ausência de possibilidade para um retorno ao mundo referencial dos leitores deixará John sem nenhuma opção: não é possível, para o último dos antigos educado em uma tradição shakespeariana já morta viver nesse admirável mundo novo. A morte de Linda e a consequente tomada de consciência de que só é possível ser feliz nessa Londres futurista caso você renuncie à sua própria individualidade fazem o protagonista perceber que não há outro caminho para ele mesmo se não, de maneira literal, a própria morte.

Aqui, contribui diretamente para a força do prognóstico o suicídio cometido por John, na cena final de Brave New World. Tivesse o Selvagem sido assassinado pelas forças repressoras dessa sociedade distópica e talvez ele pudesse tornar-se um mártir, um exemplo a ser seguido por outros habitantes igualmente insatisfeitos com o sistema político vigente. John poderia muito bem tornar-se um exemplo para Ian Helmholtz e Bernard Marx, que também se encontram ao longo de toda a trama extremamente descontentes com suas próprias vidas em Londres. No entanto, o que ocorre é justamente o contrário: Mustafá Mond revela aos dois amigos que existem outras pessoas como eles, que não conseguem adaptar-se às características dessa sociedade idílica, e oferece a ambos a possibilidade de viverem suas vidas em uma ilha distante na qual poderiam trabalhar como cientistas sem serem incomodados. A oportunidade do exílio voluntário anima os dois amigos que imediatamente aceitam a oferta.

A opção do exílio não é permitida a John. Quando o protagonista solicita a oportunidade de ir para as ilhas, Mustafá Mond lhe nega o pedido sob a justificativa de que ele gostaria de continuar com as experiências sobre a inserção do Selvagem na sociedade londrina, motivo pelo qual o rapaz havia sido trazido da reserva por Bernard Marx. Em uma conversa com Ian Helmholtz e com o próprio Bernard, o selvagem expressa o seu desejo de ser levado embora, mesmo contra a vontade do controlador mundial.

Fui falar com o Administrador esta manhã - disse, por fim, o Selvagem.

- Para quê?

- Para perguntar se eu não poderia ir com vocês para as ilhas.

- E que disse ele? - perguntou vivamente Helmholtz.

O Selvagem sacudiu a cabeça.

- Não consentiu.

- Por que não?

- Disse que queria continuar a experiência. Mas diabos me levem - acrescentou o Selvagem, com súbito furor - diabos me levem se eu continuar a servir de objeto de experiências. Nem por todos os Administradores do mundo. Também parto amanhã.

- Mas para onde? - perguntaram os dois ao mesmo tempo. 
Após a perda da mãe e a conversa com o administrador mundial que culmina com a negação da permissão para exilar-se nas ilhas juntamente com Ian e Bernard, o Selvagem torna-se um eremita e busca fugir do alcance e dos olhos dos outros habitantes de Londres. O local escolhido pelo protagonista é um antigo farol isolado, longe das partes mais movimentadas da cidade. Da negação desse direito à solidão voluntária, condição básica para a experiência da introspecção tão valorizada pelo próprio protagonista, John sofre um duro golpe em sua raison d' etre. Se a possibilidade de viver nessa sociedade distópica fecha-se no momento em que há certa tomada de consciência de que Lenina jamais será capaz de corresponder ao seu amor ativada pelo episódio da morte de Linda, sua mãe por outro lado, Mustafá Mond nega-lhe qualquer possibilidade de fuga da sua condição presente sob o pretexto de que não seria desejável parar a experiência que estava em curso da qual o Selvagem era o objeto central. A indagação que nos resta antes de avançarmos para a alegoria do suicídio do Selvagem é: qual seria exatamente essa experiência e teria ela alguma relação com o suicídio do protagonista?

A primeira pergunta é de difícil resposta. A experiência em si é apenas tematizada no momento em que Bernard viaja para a reserva natural e traz John consigo de volta para Londres. A ideia de Mustafá Mond, em linhas gerais, é procurar perceber como um indivíduo não condicionado pelos múltiplos e variados processos científicos aplicados a todos os outros cidadãos desse admirável mundo novo se comportaria no interior dessa sociedade. No entanto, a resposta para essa pergunta no momento do diálogo entre ambos já está dada: sua inserção na dinâmica social mundo novista é completamente fracassada e, para além disso, oriundo de uma educação baseada em obras banidas pelo regime, o Selvagem parece ser incapaz de compreender as vantagens do sistema social vigente nessa Londres futurista. Dessa forma, se isso é realmente válido, o questionamento a ser feito sobre as intenções de Mond deve ser alterado para: por que então, se a experiência já havia apresentado resultados consideravelmente sólidos, manter o Selvagem em Londres?

A resposta a essa pergunta pode ser vislumbrada sob a perspectiva da relação estabelecida pelo narrador entre o protagonista e o leitor implícito ao longo da trama. Essa relação, conforme discutido nos capítulos anteriores, move esse leitor implícito no interior da trama para tornar o prognósticoencenado pelo romance mais poderoso do ponto de vista argumentativo. Ser capaz de trazer o leitor para dentro da história é fundamental para a ativação de um imaginário no qual o prognóstico encenado seja percebido não apenas como o produto final de uma operação ficcionalizante, mas sim como um romance que diga respeito à vida concreta desses homens e mulheres em um futuro próximo. Os elementos para a ativação do imaginário que perpetua essas obras como artefatos ou alegorias que dizem respeito à experiência humana encontram-se, como já pode ter ficado claro para alguns leitores, no interior delas mesmas. Isso não significa dizer que esses atos de fingir que compõem a narrativa romanesca construída em Brave New World não sejam, eles mesmos, históricos. Todavia, o que há de histórico nessa e nas outras obras por nós analisadas não pode ser compreendido a partir da teoria do reflexo. Essa tentação é poderosa, especialmente quando o assunto são esses romances distópicos que foram e ainda são extensamente associados a certo projeto estético satírico. ${ }^{14}$ No lugar da sátira, o que estamos propondo como chave interpretativa para essas obras consiste justamente na via aposta: pensar certa dimensão propositiva desses romances a partir de um método crítico que tem submetido essas obras a um julgamento. Só a partir dessa atividade que mescla investigação histórica e exercício crítico é que seremos capazes

13 No original, em inglês, encontra-se: "I went to see the controller this morning,' said the Savage at last

'What for?'

'To ask if I mightn't go to the islands with you.'

'And what did he say?' Asked Helmholtz eagerly.

The Savage shook his head. 'He wouldn't let me.'

'Why not?'

'He said he wanted to go on with the experiment. But I'm damned,' the savage added, with sudden fury. 'I'm damned if I'll go on being experimented with. Not for all controllers in the World. I shall go away tomorrow too.

'But where?' the others asked in unison.

'The Savage struggled his shoulder. 'Anywhere I don't care. So long as I can be alone."

14 Uma longa tradição de trabalhos produzidos sobre a obra de Aldous Huxley segue por esse caminho e alguns inclusive já foram citados no começo desse trabalho. Para um outro exemplo, ver: (FIRCHOW, 1972). 
Artigos

de responder não apenas por que Mustafá Mond decide dar sequência ao experimento, mas também qual é o significado disso para o desenvolvimento do prognóstico encenado em Brave New World.

O prosseguimento da experiência reduz consideravelmente o espaço de ação do Selvagem. Cuidadosamente selecionada, a imagem do experimento possui múltiplas funções no interior da construção do encerramento do enredo. A principal talvez seja mostrar como, embora John faça questão de manter-se como um indivíduo (self) livre dos desígnios de Mond, não há escapatória para o destino prognosticado pela trama ficcionalmente construída por Huxley. A ideia da experiência implica afirmar que o Selvagem, o representante último da tradição shakespereana, não passa de uma cobaia nesse novo mundo e seu fim está condicionado às vontades e desejos dessa sociedade distópica e de seus administradores. Sua última opção, a fuga para o farol afastado da cidade é rapidamente frustrada quando a notícia se espalha pela cidade. Totalmente sem opções e vendo-se destituído de qualquer chance de retorno ao mundo referencial, o leitor implícito e John caminham em direção a uma estrada sem volta. Após o lançamento de um filme sobre sua experiência em Londres, de uma hora para a outra, o protagonista torna-se praticamente uma atração de circo, algo exótico no interior desse mundo novo do qual ele percebera a poucas páginas que não poderia fazer parte.

"Como num pesadelo, as dúzias tornavam-se vintenas, centenas. O Selvagem recuara em busca de abrigo; e agora, na
posição de um animal acossado, encostara-se na parede do farol, dirigindo o olhar de um rosto a outro, num horror
mudo, como um homem demente. [...]
- Vão embora! - bradou.
O macaco falara; houve uma explosão de risos e aplausos. "Este bom Selvagem! Hurra! Hurra!" (Ibid, p. 209-210)

Essa demência do Selvagem não surge nesse ponto específico da trama. Na realidade, esse processo no qual o protagonista vai cada vez mais abrindo mão de sua racionalidade para tentar fugir dessa realidade distópica encontra seu ápice nesse momento. Sem esperanças de fuga e sem conseguir vislumbrar outra opção na qual consiga tornar-se algo mais do que mero objeto de uma experiência científica, John vai progressivamente tornando-se um Selvagem não apenas aos olhos desses habitantes da Londres futurista, mas, especialmente, sob sua própria perspectiva. Assim, começa a desenhar-se mais claramente a forma pela qual essa estética do prognóstico manifesta-se na narrativa de Brave New World: a partir de um longo processo no qual John, trazido da reserva natural para o mundo civilizado, fracassa em intregrar-se a essa sociedade e vê seu mundo, ou aquilo que ele percebe como o mundo a sua volta, desintegrar-se diante de seus olhos. Esse fracasso da integração de John na sociedade distópica, manifestada recorrentemente pelo narrador, quando descreve a morte de sua mãe, suas desventuras amorosas com Lenina ou a conversa com o Administrador Mundial, aparece recorrentemente na dicotomia entre as maneiras pelas quais se escolhe nomear o protagonista. Nesse ponto do enredo, já não há mais John. Tudo o que vemos sobrar diante de nós, leitores, é a imagem do Selvagem perdido, confuso e irritado por ser reduzido a um experimento qualquer. Acentua-se a sensação claustrofóbica de que não há nenhuma outra opção possível tanto para o herói quanto para o leitor implícito.

As metáforas empregadas ao final do romance, especialmente na passagem destacada, são bastante elucidativas nesse sentido. A vida do Selvagem havia tornado-se um pesadelo, justamente porque havia deixado de ser um homem para tornar-se um animal acossado, ou nas palavras do público que o assiste, um bom Selvagem. O processo de desconstrução, ou morte, de sua individualidade (self) terá apenas sua conclusão no momento do suicídio. Seu princípio é fruto das experiências nunca nomeadas claramente e realizadas pelo Administrador Mundial. Essas experiências, elas mesmas, retiram de John sua condição humana para tornálo praticamente um animal sob os olhos dos demais habitantes da sociedade distópica. Invertendo perversamente a lógica do mundo referencial, o narrador transforma o último representante da tradição shakespereana em um bom Selvagem, removendo todo e qualquer direito a um traço humano em sua descrição nessa

15 No original, em inglês, encontra-se: "As in a nightmare, the dozens became scores, the scores hundreds. The Savage retreated towards cover, and now, in the posture of an animal at bay, stood with his back to the wall of the lighthouse, staring from face to face in speechless horror, like a man out of his senses. [...]"

'Go away!' He shouted.

The ape had spoken; there was a burst of laughter and hand-clapping. Good old Savage! Huraah, Huraah!” (tradução nossa) 
passagem. Não é mais John, o indivíduo leitor de Shakespeare ${ }^{16}$, quem fala, mas sim um macaco do qual só se pode rir e aplaudir as curiosas e incompreensíveis peripécias.

Por fim, vendo um igual e considerado como tal a partir da cuidadosa relação de alteridade construída ao longo do romance ser reduzido à condição animal, o leitor implícito seguirá pelas últimas páginas da trama até encontrar o momento derradeiro em que o prognóstico encenadoem Brave New Worldassume seu sentido último: o da erradicação da individualidade (self). Esse sentido tem sua conclusão justamente com o suicídio do Selvagem, pois este é o momento derradeiro no qual há o rompimento definitivo dessa relação entre o protagonista e o leitor implícito que causa um choque no leitor, fazendo com que ele considere o destino do Selvagem como um possível destino para si mesmo e, dessa forma, imbuindo esse prognóstico de uma significativa força narrativa, tornando-o algo mais do que uma mera encenação, mesmo que ao fim e ao cabo, ele não passe como toda obra ficcional de uma grande encenação.

\section{Referências:}

ARENDT, Hannah. A Vida do espírito: o pensar, o querer e o julgar. São Paulo: Civilização brasileira, 2008.

AUERBACH, Erich. Mimesis: a representação da realidade na literatura ocidental. São Paulo, Perspectiva, 2011.

BERLIN, Isaiah. Limites da utopia: capitulos da história das ideias. São Paulo, Companhia das Letras, 1991.

. BLOOM, Harold. Introduction. In: William Shakespeare's Hamlet. New York and Philadelphia: Chelsea house publishers, 1986

CALDER, Jenni. Huxley and Orwell: Brave New World and Nineteen Eighty-Four. London, Edward Arnold, 1976

FIRCHOW, Peter. Aldous Huxley: satirist and novelist. Minneapolis: University of Minessota Press, 1972.

Reluctant Modernists: Aldous Huxley and Some Contemporaries. Edited by Evelyn S. Firchow and Bernfried Nugel. Berlin, LIT VERLAG, 2002.

GINZBURG, Carlo. Nenhuma ilha é uma ilha: quatro visões da literatura inglesa. São Paulo: Companhia das Letras, 2004.

GRUSHOW, Ira. Brave New World and The Tempest. In: College English, Vol. 24, No. 1 (Oct, 1962), pp- 42-45. Disponível em: www.jstor.org/stable/373846

HABERMAS, Jürgen. A crise do estado de bem-estar social e o esgotamento das energias utópicas. In: Diagnósticos do tempo, seis ensaios. Rio de Janeiro, Tempo Brasileiro, 2005.

HUXLEY, Aldous. Brave New World. Essex: Longman Group \& Chatto \& Windus, 1991.

ISER, Wolfgang. O fictício e o imaginário. Trad. Johannes Kretschmer. Rio de Janeiro: EDUERJ.

KOSELLECK, Reinhart. Crítica e crise: uma contribuição à patogênese do mundo burguês. Rio de Janeiro, EDUERJ: contraponto, 1999

. Historias de conceptos. Estudios sobre semántica y pragmática del lenguaje político y social. Madrid: Editorial Trotta, 2012.

LIMA, Luiz Costa. Entre realismo y figuración: el realismo decentrado de Auerbach. In: revista Histoya y grafía, $\mathrm{n}^{\circ}$ 32, 2009, pp. 109-129

$16 \mathrm{O}$ argumento de que Shakespeare, especialmente em Hamlet, tornou-se o paradigma para toda a experiência de introspecção no interior da moderna literatura romanesca foi explorado, por exemplo, pelo excelente trabalho de Harold Bloom. "Antes de Shakespeare, as representações na literatura podiam mudar à medida que os personagens falavam, mas eles não mudavam por causa do que eles haviam dito. A representação Shakespeareana gira em torno de seus personagens ouvindo eles mesmos ao serem ouvidos por nós, e aprendendo e mudando assim como nós aprendemos e mudamos. Falstaff delicia-se tanto quanto ele nos encanta, e Hamlet muda, estudando suas próprias mudanças. Desde então, Falstaff foi o modelo inescapável para quase toda a inteligência, e Hamlet o paradigma para toda a introspecção." (grifo e tradução nossos) Cf. (BLOOM, 1986, p. 3) 
Artigos

MECKIER, Jerome. Aldous Huxley: Modern Satirical Novelist of Ideas. Edited by Peter E. Firchow and Bernfried Nugel. Berlin, LIT VERLAG, 2006.

PAVLOSKI, Evanir. Admirável Mundo Novo e a Ilha: entre o idílio e o pesadelo utópico. 362f Tese (Doutorado em Letras), Programa de Pós-graduação em Letras, Universidade Federal do Paraná. 2012

WILLIAMS, Raymond. Utopia e ficção científica. In: Cultura e sociedade: de Coleridge a Orwell. São Paulo: Editora Vozes, 2011. 